\title{
Dispositivo da maternidade: mídia e a produção pedagógica de sujeitos, práticas \\ e normas
}

\section{The dispositif of motherhood: media and pedagogical production of subjects, practices and norms}

\author{
Fabiana de Amorim Marcello*
}

\begin{abstract}
RESUMO
Este artigo tem como objetivo analisar de que maneira um dispositivo da maternidade é produzido e atualizado no espaço midiático de forma a produzir diferentes "modalidades maternas" e, a partir deles, padrões normativos. Para tanto, realizo uma análise enunciativa de dois conjuntos de materiais: um, composto por reportagens das revistas Veja e Caras sobre duas personagens mães-famosas (Vera Fischer e Xuxa) e capturadas entre 1992 e 2003; e, outro, composto por matérias retiradas da revista Crescer, no período de janeiro de 2001 a julho de 2002. Afirmo que esta normatividade é produzida a partir da relação entre as modalidades maternas e a partir do modo como os sujeitos-mãe deste dispositivo relacionam-se entre si e com os sujeitos-pai.

Palavras-chave: mídia, dispositivo da maternidade, Foucault.
\end{abstract}

\begin{abstract}
The purpose of this paper is to analyze the way in which a dispositif of motherhood is produced and updated in mediatic spaces to produce different 'maternal modes' and, then, normative patterns. With this purpose,

* Mestre e doutoranda em Educação pela Universidade Federal do Rio Grande do Sul (UFRGS). Membro do Núcleo de Estudos sobre Mídia, Educação e Subjetividade (NEMES) e
\end{abstract} bolsista do CNPq. 
I make an enunciative analysis of two sets of materials: one, consisting of articles from the weekly magazines Veja and Caras about famous mother characters (Vera Fischer and Xuxa) captured between 1992 and 2003; and another one, made up of articles taken from the magazine Crescer, between January 2001 and July 2002. I state that this normativity is produced through the relationship between the maternal modes and through the way the mother-subjects from this dispositif relate to each other and to the father-subjects.

Key-words: media, dispositif of motherhood, Foucault.

Este artigo insere-se em um campo de discussão que relaciona Educação e Comunicação à medida que partilha da idéia de que os processos educacionais e formativos estão, cada vez mais, sendo exercidos em outros espaços da cultura - e não apenas na escola, entendida, muitas vezes, como lócus exclusivo e privilegiado de ensino-aprendizagem. Nesse sentido, ao considerar o caráter nitidamente pedagógico que a mídia vem assumindo, compreendo que ela não pode ser encarada somente como meio veiculador de informações, mas também como produtora de saberes, de formas específicas de comunicar e de produzir sujeitos.

Partindo dessas considerações mais amplas, utilizo-me principalmente da obra do filósofo francês Michel Foucault e de suas produções acerca do conceito de saber, relações de poder e modos de subjetivação, para discutir, baseada em Foucault, o conceito de "dispositivo" da maternidade. Mais especificamente, o objetivo aqui é analisar de que maneira os saberes de um dispositivo da maternidade são veiculados no espaço midiático de forma a produzir, como seus objetos discursivos, sujeitos-mãe específicos (mãe homossexual, mãe adolescente, mãe solteira, etc.), bem como diferentes "modalidades maternas" (maternidade homossexual, maternidade adolescente, etc.). Interessa-me mostrar de que maneira tanto sujeitos-mães, como modalidades maternas participam ativamente da constituição normativa do dispositivo em questão, objetivando e sendo objetivados por ela, regulando e sendo regulados por ela.

Além disso, é importante destacar que o tema da maternidade (ou da maternagem) insere-se também numa discussão mais ampla acerca da formação de professores (em especial, de pedagogas e pedagogos). $\mathrm{Na}$ área da educação, há importantes trabalhos que discutem aspectos relativos à indefinição dos diversos papéis exercidos pelas educadoras, bem como a influência mútua de uns sobre os outros. De algum modo, tais papéis evidenciam uma 
"imbricação entre trabalho doméstico, maternagem e trabalho assalariado" (CARVALHO; VIANNA, 1994, p. 134). Atuando como responsáveis pela educação de crianças, as professoras "compartilham tarefas, modelos ideais de cuidados e maternagem, características e saberes culturalmente atribuídos a uma natureza feminina" (CARVALHO; VIANNA, 1994, p. 138). As autoras enfatizam o caráter político da relação entre maternagem e atuação profissional, mostrando o quanto os limites da responsabilidade das educadoras escolares podem ainda estar indefinidos e móveis.

Da mesma forma, não é raro que alunos e alunas de graduação em Pedagogia aprendam sobre teorias pedagógicas baseadas na Psicologia Evolutiva, as quais buscam promover a formação de uma criança autônoma, independente, responsável, cognitivamente competente, portanto, bem educada. Trata-se de teorias que enfatizam a importância da participação da mãe para o "desenvolvimento" destas crianças. Baseadas em uma descrição do que consideram como natural (por exemplo, a sincronia entre mãe e filho), algumas destas teorias pedagógicas manifestam que a tarefa das mães está relacionada com uma forma de educação "indireta e de diligência no que se refere à criação de circunstâncias (emocionais e físicas) que estimulem a aprendizagem de seus filhos e a aquisição de certas características" (wOOLLETT; PHOENIX, 1999, p. 89). Ao mesmo tempo, este discurso é apreendido pelas instituições escolares de forma a considerar que as mães constituem-se, muitas vezes, como "origem dos problemas evolutivos" (WOOLLETT; PHOENIX, 1999, p. 87), conduzindo, assim, a uma fácil culpabilização da mãe, no caso de a evolução de seu filho não se ajustar àqueles níveis referidos.

Obviamente, a presença de um caráter maternal da formação de pedagogos e pedagogas não é central aqui, neste artigo. Porém, ela merece ser ressaltada apenas à medida que faz ver que a discussão acerca da produção contemporânea da maternidade é reiterada em muitos espaços da cultura. Se observarmos com atenção, é possível observar de que modo um grande aparato discursivo acerca da maternidade está presente e é repetido em várias instâncias: na escola ou na universidade (como foi dito), em programas governamentais, em dogmas religiosos e, como nos interessa aqui, na mídia contemporânea.

Desta forma, pretendi fazer uma análise discursiva de dois conjuntos de materiais. O primeiro conjunto é composto por narrativas midiáticas retiradas de reportagens das revistas $\operatorname{Veja}^{1}$ e $\operatorname{Caras}^{2}$, sobre duas personagens-mães

1 Revista semanal, publicada pela Editora Abril, que aborda assuntos variados - desde notícias políticas (do país e do exterior), entrevistas com personalidades das mais diversas áreas 
famosas: Xuxa e Vera Fischer. As reportagens foram extraídas a partir do momento em que cada uma destas mulheres tornou-se visível como mãe. No caso de Xuxa, as matérias foram selecionadas a partir de 1998 e de Vera Fischer, 1992. O segundo conjunto de materiais é composto por reportagens retiradas de uma revista que se propõe a ensinar e aperfeiçoar os cuidados e a atenção sobre a prática da maternidade: selecionei a revista Crescer $^{3}$ publicada no período de janeiro de 2001 a julho de 2002.

No processo de análise, focalizo-me, sobretudo, no funcionamento das curvas de visibilidade e dos regimes de enunciabilidade, como elementos ${ }^{4}$ que vêm a compor os saberes deste dispositivo, já que se constituem como produtores genuínos de enunciados (e, por sua vez, de discursos). São estas curvas e regimes que fazem ver e dizer a maternidade e os sujeitos-mãe; são estas curvas e regimes, pois, que os contituem (sujeitos e maternidades) como objetos discursivos. Da mesma forma, discuto atentamente acerca das linhas de força, pois elas estão intimamente relacionadas com a dimensão do poder e, por isso, atingem todos os espaços do dispositivo; o poder atua como força "onipresente", no sentido de se produzir a cada momento, a partir da complexa relação entre todos os pontos de um dispositivo. Enfim, à medida que agregam instâncias de saber e de poder, é o conjunto destas curvas, regimes e linhas que dizem respeito prioritariamente à criação e à disposição estratégica de práticas discursivas no dispositivo da maternidade.

Embora não sejam o foco principal desse artigo, busco discutir, mesmo que brevemente, outros dois componentes do conceito: linhas de subjetivida$d e$, as quais permitem que se produza o sujeito-mãe e fazem com que ele encontre condições de enunciar-se e ser enunciado pelo discurso e pelas relações saber-poder que lhe são correlatos; e linhas de ruptura, que assinalam o caráter de resistência imanente a qualquer dispositivo.

Assim, mostro que o conjunto destas linhas, curvas e regimes instauram processos de normatização, principalmente, de duas maneiras: uma, na rela-

(medicina, psicologia, literatura, comunicação, direito etc.), destaques de eventos sociais, polêmicas atuais e até mesmo indicações de livros, de peças teatrais e de filmes cinematográficos. A revista Veja é uma das mais tradicionais do país, estando no mercado há 35 anos.

2 Revista semanal, publicada por uma editora própria, teve sua primeira publicação em 1990. Destina-se a relatar a vida, preferencialmente íntima, de artistas e pessoas famosas.

3 Publicada pela Editora Globo mensalmente desde 1990. Um dos motivos pelos quais esta revista foi escolhida para pertencer ao corpus de análise deve-se ao fato de que, dentre todas as publicações destinadas ao cuidado do infantil, a revista Crescer é a de maior vendagem no país (informação obtida no site da revista).

4 Os cinco elementos que indico como constituintes do conceito foucaultiano de dispositivo procede dos trabalhos de Gilles Deleuze (1999) e Sandra Corazza (2000). 
ção que as modalidades maternas estabelecem entre si e, outra, a partir da forma pela qual a figura paterna ganha visibilidade e enunciabilidade. Inicio, portanto, caracterizando um conjunto de elementos normativos que são construídos a partir do momento em que tais modalidades maternas podem ser efetivamente comparadas, confrontadas entre si. Após, indico como a figura do pai é essencial para a construção da normatividade materna, no sentido de que, antes de promover um apagamento da figura paterna, o dispositivo da maternidade vale-se dela para articular de modo comparativo práticas tidas como saudáveis, boas, aconselháveis e propícias à maternidade. Ou seja, valese dela para valorar, moralizar, antes de mais nada, modos de ser mulher em nosso tempo.

\section{Relações entre modalidades maternas: produção da norma, atuali- zação do dispositivo}

No conjunto de materiais analisados, foi possível evidenciar que uma das formas de constituir o par normalidade/anormalidade é dar visibilidade e enunciabilidade aos sujeitos mães-adolescentes e, conseqüentemente, à modalidade materna "mãe-adolescente". Considerado como um dos elementos centrais para a produtividade da norma no dispositivo da maternidade, o sujeito-mulher adolescente, da forma como enunciado, evidencia características não condizentes com uma noção de maternidade hegemônica, normativa. É válido compreender sua produtividade em relação à colocação em discurso de aspectos normativos da maternidade. Ou seja, é válido, portanto, caracterizar a dinâmica que o dispositivo suscita ao fazer destas peculiaridades do sujeito-mulher a sua condição de produção de um sujeito-mãe "anormal".

Para tais afirmações, valho-me principalmente dos apontamentos feitos sobre o corpo da adolescente grávida. A revista Crescer assegura que, "em termos biológicos, uma gravidez na adolescência é considerada, pelos obstetras, como uma condição de risco aumentado" (MENINAS..., 2001, p. 24). Dessa gestação, podem decorrer várias patologias, entre elas "a necessidade de cesárea porque a bacia - em vista da imaturidade óssea - não abre espaço para a passagem do bebê" (MENINAS..., 2001, p. 24). Quanto aos recém-nascidos, "correm o risco de ser prematuros e apresentar baixo peso" (MENINAS..., 2001, p. 24) e também "pode acontecer de não serem amamentados no peito porque 
as glândulas mamárias da mãe ainda não se desenvolveram completamente, comprometendo a produção do leite" (MENINAS..., 2001, p. 24).

É válido apontar que, de um modo sutil, se renovam estratégias semelhantes àquelas usadas por enunciados médicos - oriundos do século XVII que evidenciavam a vocação "natural" da mulher à maternidade. Tais enunciados vinham compor discursos sobre a anatomia feminina para comprovar a tendência da mulher a tornar-se mãe. Tratava-se de confirmar, cientificamente, a natureza da maternidade a partir da idéia de que a "essência se define por funções orgânicas específicas” (NUNES, 2000, p. 39). Considerava-se que a mulher por ter, entre outras características, uma "bacia alongada", tinha como vocação imperativa a maternidade. Porém, aqui, a bacia imatura, menor, mostra a tendência "natural" a não poder ser mãe na adolescência. Estes sentidos, evidenciados discursivamente, entram em choque com outros (deste mesmo dispositivo) ligados à forma igualmente "natural" com que o corpo da mulher se adapta à gravidez e ao parto.

Em um processo de replicação de saberes médicos, legitima-se um certo caráter normativo. Demonstra-se, por meio da ciência, que a mulher-adolescente, preferencialmente, não deve ser mãe, pois sua imaturidade não é apenas de ordem psicológica, mas também relativa a seus ossos, a seu corpo, a suas células. Como é característico das estratégias de funcionamento da norma, procuram-se as marcas da anormalidade "em cada corpo" (VEIGA NETO, 2001, p. 1), para que posteriormente "cada corpo se atribua um lugar nas intricadas grades de classificação dos desvios, das patologias, das deficiências, das qualidades, das virtudes, dos vícios" (veIGA NETO, 2001, p. 1). O que interessa é a forma como são atribuídas tais marcas aos corpos maternos, que critérios são selecionados para tanto e que efeitos de poder-saber são constituídos a partir disso.

Pode-se afirmar, assim, que as linhas de subjetividade encontram-se delineadas por estas estratégias de poder-saber, compondo trajetos que evidenciam, para o sujeito-mãe, que cuidar de si é, pois, cuidar do outro (do filho). Trata-se, portanto, de assinalar, de fixar normativamente tais marcas aos corpos (seja a bacia, sejam as glândulas mamárias) porque elas indicam a possibilidade de prejudicar o bebê. Instituída assim a norma, cabe à mãe discernir e concluir sua anormalidade, porque isso está ligado ao prejuízo que ela (e seu corpo anormal) podem causar ao filho. Na sua condição de anormal, tais sujeitos-mãe "impedem a satisfação de ser totalmente satisfatória, (...), poluem a alegria [neste caso, da maternidade normativa] com angústia" (BAUMAN, 1998, p. 27).

Ao tornar esta modalidade materna alvo e controle dos discursos, um jogo de forças é acionado por este dispositivo justamente para tirá-la de uma 
espécie de exterioridade. Controlar pelo discurso é isso: é fazer maternidadeadolescente algo inteligível, acessível, familiar; visível e enunciável pelo discurso e pelo jogo de forças que lhe é correlato. "Ao fazer de um desconhecido um conhecido anormal, a norma faz desse anormal mais um caso seu" (VEIGA NETO, 2001, p. 115). Assim, é possível dizer que o anormal faz parte da norma, ele a constitui; é possível dizer que o anormal está, prioritariamente, sob a égide da norma (VEIGA NETO, 2001, p. 115).

Se a maternidade-adolescente pode ser aqui ressaltada por sua característica de imaturidade, por outro lado, há certas práticas maternas pré-adolescentes que evidenciam o contrário. Refiro-me especialmente a brincadeiras de faz-de-conta, nas quais meninas entre seis e oito anos investem em "treino para o desempenho de funções que a criança exercerá na vida adulta, como comandante ou comandada" (NA BRINCADEIRA..., 2001, p. 77). A partir do destaque dado a essas brincadeiras de meninas (sic), evidencia-se como o dispositivo da maternidade aplica-se na tarefa de compor a normatividade.

\begin{abstract}
Sissi [a menina] e Larissa [a boneca] reproduzem de fato a maternidade com incrível realidade. A pequena mamãe conversa amorosamente com sua filhinha, repetindo seus choramingos e balbucios, faz a boneca coçar os olhinhos quando está com sono e, quando sai para um passeio e encontra outro bebê no colo por perto, apresenta-o para Larissa. Na rotina desse faz-de-conta, entram todos os cuidados que as mães de verdade costumam dispensar aos seus bebês: trocas de fralda, limpeza no bumbum, banho, roupa limpa, comidinhas, hora de arrotar, canções para dormir (NA BRINCADEIRA..., 2001, p. 77).
\end{abstract}

É importante dar a ver essa "maternidade-de-mentirinha", porque com ela são traçadas formas de cumprir a norma ou de colocá-la em funcionamento. Nada imatura, a menina mostra uma espécie de seriedade, de rigor ao representar-se como mãe. Mostra que, desde pequena, o sujeito-mulher sabe, efetivamente, como tratar os filhos, como cuidar deles e o quanto isso lhe é motivo de prazer, orgulho e naturalidade (NA BRINCADEIRA..., 2001, p. 77). A menina que assume mesmo o papel de mãe inclusive demonstra o amor incondicional (NA BRINCADEIRA..., 2001, p. 77) - característico da maternidade normativa - à pequena filha de plástico. Os adjetivos e expressões empregados são ilustrativos: incrível realidade (sic), mães de verdade (sic), conversas amorosas (sic). Ao retratar o jogo saudável (Idem) de brincar de mãe, a nor- 
ma vai encontrando cada vez mais espaços para sua afirmação. Ironicamente, a prosaica brincadeira infantil serve de suporte para uma normatividade materna ligada a questões de responsabilidade e maturidade (precoce): a mesma norma, pois, que irá afirmar patologia da maternidade-adolescente.

Neste dispositivo, há a necessidade de expor a maternidade em suas diferenças, porque, mesmo minimamente, algumas delas poderão ser consideradas como anômalas ou talvez distorcidas em relação a um padrão. Daí a afirmar que nem todas as modalidades maternas são objetivadas como patológicas ou como não-desejáveis, uma vez que têm suas visibilidade e enunciabilidade ligadas à capacidade ou à probalidade de incorporarem-se ao tal padrão. Nestes casos, a instauração de uma normatividade materna envolve a objetivação e a organização de sentidos considerados como temporários e móveis, passíveis, portanto, de transformações.

Partindo dessa idéia, afirmo que algumas das objetivações podem ser caracterizadas quase como estados anormais de maternidade; algo que o sujeito do discurso pode enfrentar, ultrapassar, para que dada maternidade possa ser plenamente vivenciada (porém, agora, na condição de normativa). As diferenças tornam-se, assim, estados de diferença. Refiro-me, em especial, a casos que não dizem respeito a modalidades maternas problemáticas, mas a modalidades que podem tornar-se problemáticas, dependendo da maneira como forem conduzidas. Por este motivo - para não se tornar uma patologia ou uma doença -, muitas das modalidades maternas se constituem como objetos a inquirir e a administrar neste dispositivo. A partir dos conselhos e do conjunto maior de saberes produzidos por estas objetivações, se busca normatizar práticas ou sujeitos maternos, tendo em vista que tais dicas servem para afastar a hipótese de anormalidade. É aí que o dispositivo que materniza encontra condições para sua atualização e antecipação, à medida que as linhas de força tornam-se mais hábeis em sua tarefa de capturar os sujeitos, inclusive aqueles que podem se tornar, eventualmente, anormais.

Um exemplo pode ser útil para ilustrar esta afirmação. A revista Crescer afirma que "por mais preparada que esteja para enfrentar tudo em duplicata, mãe de filhos gêmeos deve saber que terá pela frente uma maratona sem trégua" (ALEGRIA..., 2001, p. 48). Para esta modalidade materna (cujo sujeito é mãe-de-gêmeos), será exigida uma rigorosa disciplina: "é preciso organizar as mamadas em dose dupla, atender a choros dobrados, trocar fraldas em duplicata. Nada grave. É na prática que a mãe vai aprendendo, relaxando [!] e descobrindo que pode, sim, dar conta do recado" (ALEGRIA..., 2001, p. 48). Porém, "passado o sufoco inicial, só é preciso paciência, confiança e bom senso para, então, desfrutar dessa surpreendente experiência de ser mãe de 
dois filhos que nascem ao mesmo tempo" (ALEGRIA..., 2001, p. 50) ou, talvez, "para poder aproveitar o máximo a alegria de ser maternidade em dobro" (ALEGRIA..., 2001, p. 50).

Em um outro caso: "a futura mamãe que chega ao consultório [médico] pesando mais do que seria desejado para sua altura e constituição física terá, em primeiro lugar, de enfrentar o desafio de engordar o mínimo necessário para suprir suas necessidades calóricas e fornecer os nutrientes que o bebê precisa para se desenvolver" (o DESAFIO..., 2001, p. 20). Esta mulher estará, ainda, "mais propensa a sentir o impacto dos desconfortos típicos da gestação, poderá enfrentar problemas na hora do parto e na sua recuperação e, conforme o caso, colocar em risco a saúde do filho" (o DESAFIO..., 2001, p. 20).

Estes saberes, ciosamente articulados, provocam a avaliação dos sujeitos, bem como calculam o risco de se tornarem anormais (algo muito mais perigoso do que um estado de anormalidade). É assinalada a importância da cautela, da precaução, pois é imprescindível tornar visível e enunciável o que vai ou o que pode acontecer (como no exemplo da gestante acima do peso). $\mathrm{O}$ controle, seja do corpo, seja das atitudes do sujeito-mãe, não é, pois, perdido de vista, já que dele vai depender a condição normativa de dada modalidade. Interessa saber, ainda, de que maneira se consegue controlar os passos do sujeito-mãe e dizer-lhe que a diferença até pode ser bem-vinda (como no caso da mãe-de-gêmeos), desde que sejam antecipadas as formas de administrá-la. Tais considerações apontam para o fato que "o anormal está na norma" (EWALD, 1996, p. 87), também porque ele pôde ser, de algum modo, antecipado, previsto, circunscrito. É, portanto, a possibilidade de tornar-se um anormal que indica os limites que compõem a norma.

Outro tema bastante recorrente na edificação normativa deste dispositivo diz respeito à questão da amamentação. Assim, "o ginecologista Daniel Klotzel, do Grupo de Apoio à Maternidade e Paternidade, de São Paulo informa que "mantendo uma alimentação balanceada perde-se peso só com a amamentação"” (o CORPO..., 1999, p. 212). Eis a necessidade de atualização do dispositivo: não se trata apenas de mostrar os benefícios do leite materno para o bebê, mas também capturar o sujeito-mãe que não se submete apenas a essa informação. O dispositivo da maternidade, já que entrelaçado ao "dispositivo pedagógico da mídia" (FISCHER, 1997) - a partir da legitimação do dito pelo especialista que lhe é característica -, produz novos elementos acerca de uma constituição normativa da maternidade ligada à amamentação. Para esta produção, a qual eu chamaria de movimento de renovação, o dispositivo da maternidade vale-se de um "imperativo da beleza feminina" (FISCHER, 1997). Nesse sentido, as forças e as relações de poder, aqui em questão, são ardilo- 
sas, porque encontram e promovem formas sempre fugazes de capturar os sujeitos-mãe. Para os sujeitos-mãe mais "relapsos", "que deixaram de amamentar só para poder malhar pesado" [para que o corpo voltasse ao normal mais rapidamente], "a professora de Educação Física Helena Mangini afirma que "para estas mulheres, a melhor recomendação [grifo meu] é não ter filho" (FISCHER, 1997). Mais uma vez, trata-se da ameaça, baseada em uma previsão, sustentando a garantia de não ter que se conviver com um anormal.

Não são as revistas, isoladamente, como aparatos de visibilidade, que efetuam a atualização do dispositivo. Há, pela mídia, uma apropriação discursiva de diversos campos que produzem saberes (como a medicina, por exemplo), mas não apenas isso. No caso desta matéria, podemos dizer que sua condição de existência é garantida por outros sentidos, ao apropriar-se de ditos que remetem a enunciados do campo da Medicina, ao entrelaçá-los a outros (que, por sua vez, remetem a enunciados do campo da Educação Física) e, por fim, ao articulá-los a personalidades famosas. Mesmo que frágeis, há nestas reportagens um "encaixe", uma econômica e produtiva articulação de informações e imagens. Não se trata de uma replicação discursiva isolada e única, mas de múltiplas, que, quando concatenadas, acabam favorecendo a constituição de novas discursividades maternas. Esse movimento só é possível de ser realizado porque há sujeitos que insistem em escapar do dispositivo da maternidade (por isso, ele há de se valer de saberes de outros dispositivos). É bastante provável que pudéssemos nos referir à existência de um dispositivo da feminilidade ${ }^{5}$ em nossa época, talvez fosse para suas estratégias de saber-poder-subjetivação que estes sujeitos escapariam; eventualmente, estes dois dispositivos (da maternidade e da feminilidade) estariam competindo e tensionando sentidos entre si.

Outra maneira de produzir a normatividade materna envolve necessariamente o entrelaçamento das linhas, curvas e os regimes no que diz respeito à instituição da linguagem e à sua disposição. Isso significa afirmar que o fato de incitar, de fazer ver e de fazer falar está ligado à constituição de saberes deste dispositivo que geralmente lhe é correlata. Mais do que isso, organizar sentidos, selecionar palavras ou expressões sobre uma maternidade ou outra envolve qualificar, ajuizar e fazer-lhes atribuições específicas. Pode-se dizer que a norma, como efeito das relações de força, institui a linguagem, assim como a linguagem institui a norma.

5 No caso, trata-se de um dispositivo que colocaria em questão, em nosso tempo, modos de produzir corpos femininos e uma estética específica a eles relacionada, entre outras coisas. 
Vejamos algumas destas articulações. No caso da "mãe que tem um bebê nos braços e outro a caminho" (UM BEBÊ..., 2001, p. 30), há problemas a enfrentar, mas "no balanço geral, ao que tudo indica, é bom, sim, ter um filho seguidinho do outro, [ou seja], a mulher não precisa se desesperar" (UM BEBÊ..., 2001, p. 30). Já para aquela mãe que "começa a gestação já em briga com a balança, vai precisar fazer um pré-natal supercuidadoso, manter uma alimentação muito bem equilibrada e praticar exercícios com regularidade" (o DESAFIO..., 2001, p. 20). Em relação à mãe que amamenta sem seguir um horário estipulado, ela dá ao seu bebê a possibilidade de "se alimenta[r] quando realmente tem vontade e [ele] não precisa amargar um período de fome apenas porque ainda não chegou a hora estipulada" (MAMÃE..., 2002, p. 28). Até mesmo porque"um bebê mais calmo na hora de mamar, sem aquela voracidade dos famintos, irá sugar com mais tranquilidade o seio" (MAMÃE..., 2002, p. 28). A mãe que adota esta rotina afirma: "deixei que meus filhos estabelecessem a rotina das mamadas. A gente fica meio em função do bebê, mas acho que é melhor para ele" (UM BEBÊ..., 2001, p. 29). Em relação à mãe de gêmeos: “o colo é um momento de exclusividade. Nada de dividi-lo” (ALEGRIA..., 2001, p. 48).

Enfim, nesse conjunto atribulado, anárquico e desorganizado de informações - que consistem em adjetivar práticas e criar sentidos a partir disso a norma é estabelecida. Mais do que isso, é tornada visível sutilmente nas páginas das revistas. Combinadas, as enunciações relacionam-se a uma normatividade que significa o cuidado acentuado de uma gestação, a aversão ao sofrimento da criança e o resguardo mítico do colo materno acolhedor.

No caso especial entre maternidade e vida profissional, para a mãe que gera um filho quando o outro ainda é pequeno, "o melhor a fazer é 'abrir um parênteses' - sem culpa - para se dedicar aos filhos, pelo menos, nos seus primeiros anos de vida"' (UM BEBÊ..., 2001, p. 33). As linhas de força, devidamente organizadas e distribuídas pelas curvas de visibilidade e pelos regimes de enunciabilidade, permitem que estes ditos individuais transformemse em práticas normativas - afinal, é também esse o objetivo da norma: tornar o particular universal. A relação entre maternidade e trabalho, transformada em norma, é legitimada com esta explicação: "quem tem dois bebês geralmente sai de cena por três anos. Os dois primeiros, para adaptar o primeiro filho à rotina e último, para adaptar o segundo [filho]" (UM BEBÊ..., 2001, p. 33). Ou seja, não basta dizer que a mãe deve dispensar sua vida profissional em favor dos filhos: há que ser feita uma explicação plausível, lógica, para tanto.

Neste caso, de mães que geram um filho quando o outro ainda é pequeno, a revista Crescer mostra que há algumas desvantagens para a mãe. Ela “precisará se 
preparar para enfrentar uma brutal redução de vida intelectual e profissional, e aceitar que $99 \%$ de sua energia estará comprometida com os cuidados maternos" (UM BEBÊ..., 2001, p. 32). Porém, as vantagens parecem ser muitas: "a mãe estará menos ansiosa e mais bem preparada para receber o bebê"; ela também vai poder "aproveitar a infra-estrutura já montada, o que acaba sendo mais econômico"; o filho mais velho, por exemplo, "vai poder escapar da superproteção materna, já que, com dois filhos pequenos, a mulher se vê forçada [grifo meu] a dividir atenções"; e, quanto ao marido, "findo o período de trabalho braçal mais duro, os irmãos fazem companhia um ao outro e a mulher fica liberada para lhe dar atenção de novo [grifo meu]" (UM BEBÊ..., 2001, p. 33).

Há de se considerar, para tanto, as questões profundamente discriminatórias que aí estão envolvidas e que podem ser entendidas a partir destas mães anônimas já referidas. É deste modo que a norma consegue se estabelecer. Como afirma François Ewald (1996, p. 86), a norma é "uma medida que simultaneamente individualiza, permite individualizar e ao mesmo tempo torna comparável". De alguma forma, na relação entre particular e universal, a composição de forças da constituição normativa se organiza, neste dispositivo, de modo a fazer com que a norma aja (ou pareça agir) sobre o sujeito individual, de maneira óbvia, lógica.

É na relação com o coletivo, mais precisamente com a generalização que se faz a partir disso, que se garante o sentido e a possibilidade de verificação desta maternidade à qual a norma se refere. Encontra-se, aí, a possibilidade de se unificar essas individualidades. Partindo dessas mães trazidas pela revista Crescer, fala-se ou murmura-se uma legitimidade em torno da importância e da concreta possibilidade de a norma ser efetuada. Nestes casos, a norma está vinculada à capacidade de sacrifício do sujeito-mãe: renunciando à sua vida profissional, a mãe garante a felicidade dos filhos. Mais uma vez, podem ser aqui caracterizadas as linhas de subjetividade deste dispositivo: cuidado de si como cuidado do outro.

\section{Relações entre maternidade e paternidade: produção da norma, ins- tauração de práticas de maternização}

Outra maneira de se estabelecer uma normatividade materna entre os sujeitos-mãe é a partir da relação que os pais estabelecem com as crianças, a 
partir da maneira pela qual cada um deles (mãe e pai) se relaciona com seus filhos. À medida que são postas lado a lado, práticas maternas e práticas paternas ganham visibilidades diferenciadas na mídia e, interessadamente, dessa relação, instituem-se ou reiteram-se, assimetricamente, normatividades do dispositivo da maternidade.

Os exemplos de Xuxa e Vera Fischer são, aqui, ilustrativos. Em uma mesma edição, a revista Caras mostra duas festas: uma de Xuxa, que celebrava o final do ano (1997) e outra de Luciano Szafir, que comemorava o seu aniversário. A primeira reportagem exibia a festividade da apresentadora e, logo após (na página seguinte, para ser mais exata), a revista mostrava a cobertura feita do aniversário de Luciano Szafir. O engajamento das curvas de visibilidade e dos regimes de enunciabilidade (que, de modo algum pode ser dito que é de autoria exclusiva da revista em questão) é facilmente entendido: se a festa de Xuxa foi oferecida apenas a "amigos e membros da sua equipe de trabalho, evidenciando uma comemoração íntima e informal" (UM GRANDE..., 1999) 6 , a de Luciano contava com "1000 convidados" (LUCIANO..., 1999); se na de Xuxa "as lembranças [da gravidez] foram o ponto alto da festa" (UM GRANDE..., 1999), a de Luciano serviu, na verdade, como "laboratório para a discoteca que Luciano vai inaugurar (...) na badalada região dos Jardins [em São Paulo]" (Luciano..., 1999). Se, "sem Sasha, Xuxa acabou ficando na festa menos de três horas - o intervalo entre uma mamada e outra da filha" (UM GRANDE..., 1999); Luciano "deve ter dançado até o amanhecer" (LUCIANO..., 1999). Se na festa de Xuxa seus convidados, "Marlene Mattos e membros da equipe, usaram camiseta com fotos da apresentadora grávida" (UM GRANDE..., 1999), na festa de Luciano, o "uniforme" era visto em "garotas usando vestidos estampados com a marca de uma vodca" (Luciano..., 1999).

Ainda nessa mesma edição da revista Caras, acima referida, mostravase duas outras festas. Porém, agora, referia-se à do aniversário de Gabriel, filho de Vera Fischer e Felipe Camargo (no caso, uma promovida pela atriz e a outra pelo ator). As frases que dão destaque aos eventos são distintas: "Paizão em tempo integral, o ator participou das brincadeiras propostas pelo animador [da festa]. Felipe não apenas se transformou em palhaço (...), como ajudou Gabriel na brincadeira do cabo-de-guerra" (FELIPE..., 1999). Em relação à atriz, privilegia-se o fato de que "ela usou um conjunto de calças com franjinhas e colete marrons e um chapéu de caubói. Contente com o sucesso de sua última tatuagem removível, no seio direito, Vera Fischer decalcou um novo

6 Não é possível indicar o número da página, pois a revista Caras não é paginada. 
desenho no braço esquerdo" (A ALEGRIA..., 1999). Na festa promovida pelo pai, este ocupou-se em dispensar "os tradicionais fotógrafos de festinhas infantis para ter o prazer de registrar todo o evento" (FELIPE... 1999). Já na festa promovida pela mãe, diz-se que ela "bailou com as amigas num grupo que ela chamou de" Las Muchachas. "Juntas dançaram axé music e, animadíssimas, encararam até o hit "carrinho de mão" (A ALEGRIA... 1999). Tal comportamento é registrado também pela revista Veja, ao pontuar que "os amigos ficaram chocados com o comportamento da atriz, que julgaram impróprio para a ocasião" (CAPítulo..., 1997, p. 102).

Se, no caso de Xuxa a figura do pai serve para reforçar sua maternidade responsável, comprometida e afetuosa, no de Vera Fischer, a figura de Felipe Camargo serve para caracterizá-la como desajustada, para transformá-la em sujeito-mãe inadequado. A questão afetiva é privilegiada na festa de Xuxa, na exaltação de sua filha que se faz durante todo o tempo. Na de Vera Fischer, porém, destaca-se o caráter festivo e despreocupado (caráter que marca também aquelas matérias que falam de sua dependência química). Neste dispositivo, não há um completo apagamento da figura paterna. Antes disso, tratase de dar visibilidade e enunciabilidade a esta figura, à medida que seu comportamento pode ser usado para pôr em funcionamento a normatividade materna.

Assegurar e manter a relação assimétrica entre as funções dirigidas aos indivíduos-mães e àquelas dirigidas aos indivíduos-pai é, pois, um dos objetivos da norma neste dispositivo. No exemplo de Vera Fischer, o ato de mostrar a amorosidade do pai com o filho, os cuidados dispensados por ele à criança, faz com que esta maternidade da qual Vera Fischer torna-se sujeito seja, de algum modo, desmerecida, desconsiderada e julgada (à medida que, assim, ela é enfatizada como desajustada e irresponsável). Aqui, faz-se da atitude paterna a anormalidade materna. Pelo mesmo motivo, no caso de Xuxa, Luciano Szafir é que é marcado por esta lógica produzida pelo dispositivo. Ou seja, de maneira oposta, faz-se da atitude paterna, a normalidade materna (da apresentadora).

Em outro caso, se Xuxa é capaz de tornar-se sujeito de uma maternidade normativa, promove-se sua colocação em discurso também como algo não plenamente desejável. Xuxa também se torna exemplar de uma anormalidade materna pelo fato de ter escolhido o pai de sua filha como um "mero reprodutor" (o MAIS..., 1997, p. 108). De forma semelhante, em sua condição de mãe famosa e extremada, de algum modo ela é sujeito de um discurso fora do padrão, desordenado à normatividade materna, já que a norma é constituída a partir de uma média (EWALD, 1996), não se podendo atingir os extremos. O 
que excede à norma será, aqui, instaurado e diagnosticado a partir da tensão promovida com a normatividade de um "dispositivo da infantilidade" (CORAZZA, 2000). Ao sujeito-mãe são exigidos cuidados em relação a seus filhos, porém estes cuidados não podem colidir com uma normalidade desejável ao infantil. Assim, em relação à filha de Xuxa afirma-se:

Sasha é constantemente exposta à curiosidade pública, em programas de televisão e fotos de revistas. No dia-a-dia, porém, vive isolada. Ela raramente sai de casa e nunca freqüenta praças ou parques, nem mesmo em companhia das babás e dos dois seguranças encarregados de seu bem-estar. Às vezes outras crianças, em geral filhos de artistas, vão brincar com ela. Quando precisa de médico, a consulta é em domicílio. Idem com as aulas de natação, feitas na piscina aquecida que Xuxa mandou construir no quarto de 130 metros quadrados que abriga a filha (O REINO..., 1999, p. 115).

De um modo ou de outro, as linhas de força capturam as tensões para continuamente produzir um discurso normativo sobre maternidade. As enunciações, constantemente tensionadas por diferentes dispositivos, entram em disputa para garantirem-se como verdadeiras, como legítimas. Os sujeitos, porém, não são capazes de se assujeitarem a discursos únicos, mas, sim, a múltiplos. A mãe inteiramente sujeitada à norma é, pois, fictícia. É justamente a fragmentação do sujeito que garante condição de possibilidade para que a prática de objetivação deste dispositivo não pare, não cesse de tentar capturar os sujeitos que enuncia.

\section{Considerações finais}

Neste artigo, procurei argumentar em favor da caracterização do dispositivo da maternidade no que diz respeito à promoção e à instauração da norma sobre as modalidades maternas que ele torna objeto discursivo. Compreendo que há uma constante inter-relação - tal como no caso da constituição de saberes - entre as curvas de visibilidade e os regimes de enunciabilidade e 
as linhas de força deste dispositivo. Isso ocorre, pois dar visibilidade aos sujeitos implica organizá-los e valorá-los e, de algum modo, hierarquizá-los.

No caso deste dispositivo, discuti que a norma é estabelecida tanto na relação entre as modalidades maternas (especialmente a partir das matérias da revista Crescer), como na relação que os sujeitos-mãe estabelecem com seus/suas parceiros/as (especialmente a partir dos exemplos das mães-famosas). Certamente isso é realizado de modo mais amplo - como pôde ser apresentado - porque há elementos menores (micro-elementos) que estão aí envolvidos. Há uma normatividade sobre o corpo feminino, sobre sua predisposição (ou não) à abdicação, à renúncia em favor do filho e até sobre o próprio perfil da mãe. Há inúmeros elementos que efetivamente são capturados pelo dispositivo para que se possa, assim, garantir a normatividade materna.

Porém, é importante sublinhar que é a partir da instauração constante e reiterada da norma que se pode afirmar a existência de processos concretos de resistência dos sujeitos - e aqui podemos ressaltar algumas críticas feitas ao trabalho de Foucault, que afirmariam que o autor concebe um sujeito que nunca "escapa", pois está sempre preso a regimes de saber e às relações de poder. Ora, se os sujeitos tivessem sido assujeitados às normas de maneira efetiva e plena não haveria a necessidade de um dispositivo que tivesse como uma de suas funções principais a produção contínua de práticas de maternização. Somente porque há resistência, no caso, de sujeitos-mãe é que o dispositivo vê a necessidade de reafirmar-se continuamente e, mais do que isso, de atualizar-se. Este é um movimento de constante atualização das relações de força, uma vez que a geração de resistência faz com que elas se cruzem com a necessidade de gerar novas formas de controle (geralmente normativo) que, por sua vez, geram novas formas de resistência, numa dinâmica incessante e circular. 


\section{REFERÊNCIAS}

A ALEGRIA de Vera Fischer. Caras, São Paulo, ed. 268, ano 7, n. 1, 1 jan. 1999.

ALEGRIA em dose dupla. Crescer, São Paulo: Globo, n. 94, p. 48-50, set. 2001.

BAUMAN, Z. O mal-estar da pós-modernidade. 1. ed. Rio de Janeiro: Zahaar, 1998.

CAPÍTULO médico. Veja, São Paulo, Abril, ed. 1512, p. 101-102,10 set. 1997.

CARVALHO, M. P.; VIANNA, C. P. Educadoras e mães de alunos: um (des)encontro. In: BRUSCHINI, C.; SORJ, B. (Orgs.). Novos olhares: mulheres e relações de gênero no Brasil. São Paulo: Fundação Carlos Chagas/Marco Zero, 1994, p.133-158.

CORAZZA, S. M. A história da infância sem fim. 1. ed. Ijuí: Unijuí, 2000.

DELEUZE, G. Que és un dispositivo? In: BALIBAR, E.; DREYFUS H.; DELEUZE, G. et al. Michel Foucault, filósofo. Barcelona: Gedisa, 1999. p. 155-163.

DROGAS e agonia no auge da vida. Veja, São Paulo: Abril, ed. 1733, p. 74-81, 9 jan. 2002.

EWALD, F. Foucault, a norma e o Direito. Lisboa: Vega, 1996.

FELIPE Camargo celebra Gabriel. Caras, São Paulo, ed. 268, ano 7, n. 1, 1 jan. 1999.

FISCHER, R. M. O estatuto pedagógico da mídia: questões de análise. Educação \& Realidade, v. 22, n. 2, p. 59-79, jul./dez. 1997.

FOUCAULT, M. O sujeito e o poder. In: DREYFUS, H.; RABINOW, P. Michel Foucault: uma trajetória filosófica (para além do estruturalismo e da hermenêutica). Rio de Janeiro: Forense Universitária, 1995. p. 231-249.

. Os intelectuais e o poder - conversa entre Michel Foucault e Gilles Deleuze.

In: . Microfisica do poder. Rio de Janeiro: Graal, 2000. p. 69-78.

LUCIANO comemora 30 anos. Caras, São Paulo, ed. 268, ano 7, n. 1, 1 jan. 1999.

MÃES DE filhos sem pais. Crescer, São Paulo: Globo, n. 93, p. 34-36, ago. 2001.

MAMÃE, eu quero mamar. Crescer, São Paulo: Globo, n. 99, p. 28-30, fev. 2002.

MENINAS que viram mães. Crescer, São Paulo: Globo, n. 88, p. 20-25, mar. 2001.

NA BRINCADEIRA de casinha. Crescer, São Paulo: Globo, n. 90, p. 76-77, maio 2001.

NUNES, S. A. O corpo do diabo entre a cruz e a caldeirinha: um estudo sobre a mulher, o masoquismo e a feminilidade. Rio de Janeiro: Civilização Brasileira, 2000.

O CORPO de antes. Veja, São Paulo: Abril, ed. 1623, p. 212, 10 nov. 1999. 
O DESAFIO do excesso do peso. Crescer, São Paulo: Globo, n. 89, p. 20-23, abr. 2001.

O MAIS novo Xou da Xuxa. Veja, São Paulo: Abril, ed. 1526, p. 106-112, 17 dez. 1997.

O REINO de Sasha. Veja, São Paulo: Abril, ed. 1609, p. 115, 4 ago. 1999.

SEM DISCUSSÃO. Veja, São Paulo: Abril, ed. 1734, p. 88, 16 jan. 2002.

SUCESSO faz milagre. Veja, São Paulo: Abril, ed. 1585, p. 80, 17 fev. 1999.

UM BEBÊ nos braços e outro a caminho. Crescer, São Paulo: Globo, n. 87, p. 30-33, fev. 2001.

UM GRANDE ano para Xuxa. Caras, São Paulo, ed. 268, ano 7, n. 1, 1 jan. 1999.

UM PAÍS de diletantes. Veja, São Paulo: Abril, ed. 1737, p. 107, 6 fev. 2002.

VALE quanto pesa. Veja, São Paulo: Abril, ed. 1572, p. 46, 11 nov. 1998.

VEIGA NETO, A. da. Incluir para excluir. In: LARROSA, J.; SKLIAR, C.(Orgs.). Habitantes de Babel: políticas e poéticas da diferença. Belo Horizonte: Autêntica, 2001. p. 105-118.

WOOLLETT, A.; PHOENIX, A. La maternidad como pedagogía: la psicologia evolutiva y los relatos de madres de niños pequeños. In: LUKE, C. (Comp.). Feminismo e pegagogías en la vida cotidiana. Madrid: Morata, 1999. p. 87-105.

Texto recebido em 10 jan. 2005 Texto aprovado em 27 mar. 2005 